1

2

3 \section{.}

.

3

\title{
Pilot scale study on UV-C inactivation of bacterial endospores and virus particles in whole milk: evaluation of system efficiency and product quality
}

\author{
Pranav Vashisht, Brahmaiah Pendyala*, Ankit Patras*, Vybhav Vipul Sudhir Gopisetty, \\ Ramasamy Ravi
}

Food Biosciences and Technology Program, Department of Agricultural and Environmental Sciences, Tennessee State University, Nashville, 37209, TN, USA

*Corresponding authors:

Ankit Patras, Ph.D.

Associate Professor, Food Science \& Engineering

Email: apatras@tnstate.edu

Tel: 1-615-963-6007; 615-707-8436

Brahmaiah Pendyala, Ph.D.

Senior Research Associate

E-mail: bpendyal@tnstate.edu

Tel: 1-615-963-6007; 419-699-6348 


\section{Abstract}

34 UV-C processing of whole milk (WM) using a designed pilot scale Dean flow system was 35 conducted at flow rates (11.88, 23.77, and $47.55 \mathrm{gph})$, Reynolds number ranges from 2890-11562 and the Dean number (at curved region) calculated as (648-2595) to inactivate bacterial endospores

37 and virus particles. Biodosimetry studies were conducted to quantify the reduction equivalent

38 fluence at selected experimental conditions. Results revealed that the fluence distribution 39 improved as flow rate increases, attributed to increase in Dean effects and turbulence intensity. 40 Microbial inactivation studies conducted at 47.55 gph showed $0.91 \pm 0.15$ and $2.14 \pm 0.19 \log$ 41 reduction/ pass for $B$. cereus endospores and T1UV phage. Linear inactivation trend was observed 42 against number of passes which clearly demonstrates equivalent fluence delivery during each pass. 43 Lipid peroxidation value and volatiles profile did not change significantly at UV fluence of 60 $44 \mathrm{~mJ} / \mathrm{cm}^{2}$. Lower E $\mathrm{EO}_{\mathrm{EO}}$ value signifies the higher electrical efficiency of the system.

45 Keywords: Pilot scale UV system; whole milk; bacterial endospores; virus particles; lipid 46 peroxidation; volatiles profile 


\section{Introduction}

57

58

59

60

61

62

63

64

65

66

67

68

69

70

71

72

73

74

75

76

77

Milk and its products are the potential source of various nutrients such as lipids, proteins, carbohydrates, vitamins, minerals, and enzymes; these components present in milk allows the growth of numerous pathogenic microorganisms (Oliver et al., 2005; Shanmugam et al., 2012; Bogahawaththa et al., 2018; Munir et al., 2019). According to Delorme et al. (2020), dairy processing needs strict quality control as contamination issues can originate at any stage of the food chain. The presence of aerobic spore-forming bacteria of the Bacillus genus in milk is consider as the major cause of deterioration of raw and pasteurized milk (Crielly et al., 1994; Cosentino et al., 1997). B. cereus is a major concern for the dairy industry because of its psychrotolerant nature, which limits the shelf life of the pasteurized milk and milk products stored at $6-7^{\circ} \mathrm{C}$ and its ability to produce toxins which makes it a potential cause for foodborne illnesses where the production of emetic and enterotoxin results in vomiting and diarrhea, respectively (Griffiths, 1992; Bilbao-Sáinz et al., 2009). According to CDC, more than 63000 cases of $B$. cereus illness are reported annually in the United States and all of them are foodborne (Scallan et al., 2011).

Pasteurization and sterilization are the most common techniques used by industries to ensure the safety of milk (Bermúdez-Aguirre et al., 2009; Choudhary and Bandla, 2012; Patras et al., 2020). The Code of Federal Regulations (3), Title 21, Section 131.3b, defines pasteurized dairy products as using properly operated equipment to heat every particle of the product to a specified temperature and held at or above that temperature for a specified time. Though these techniques are efficient and can inactivate numerous foodborne pathogens ranging from vegetative cells to viruses and spoilage causing enzymes. One problem that is found to cause a reduction in the shelf life of WM is the presence and growth of Bacillus sp. and its heat resistant spores in pasteurized, 
sterilized as well as ultra-pasteurized milk (Pettersson et al., 1996; Scheldeman et al., 2004; Cullor, 2011). The high pasteurization temperatures can easily destroy vegetative cells but can activate the spores, which leads to germination and growth (McGUIGGAN et al., 1994). Other disadvantages of pasteurization techniques are significant alteration in the sensorial and nutritional profile of the product, protein denaturation, undesired changes to milk fat globules, high operational and processing cost which makes it unfeasible for small scale dairy units (GarciaAmezquita et al., 2009; Cappozzo et al., 2015; Gunter-Ward et al., 2018). Raw dairy products are prioritized by the consumers because of their typical sensorial characteristics and other health benefits such as decreased incidence of asthma, allergies, and respiratory infections which suggest immune benefits of dairy proteins are lost upon heat processing (Buchin et al.,1998; BraunFahrländer and Von Mutius, 2011). To preserve the benefits of raw dairy products without compromising the safety warrants the study of non-thermal technology for processing of dairy products (Gunter-ward et al., 2018). Interest in light-based technologies (UV-C irradiation) for liquid food processing has exponentially grown over the years is increasing due to lower energy consumption, cost-effectiveness, minimal effect on the quality of the products (Tran and Farid, 2004; Keyser et al., 2008; Corrales et al., 2012; Feng et al., 2013; Ochoa-Velasco et al., 2014; Jermann et al., 2015; Islam et al., 2016). Several federal agencies have approved the use of UV-C technology for milk treatment. For example, European Food Safety Authority (EFSA) approved the use of UV-C at $253.7 \mathrm{~nm}$ for milk processing post pasteurization for the extension of shelf life and to improve the nutritional value as it increases the vitamin D3 content in the product (EFSA, 2016, and Koutchma, 2018). Food Safety and Standards Authority of India approved the UV-C processing of raw milk processed via the Sure Pure UV system (Koutchma, 2018). In USA, any new technology for processing of grade A milk has to go through PMO and FDA clearance. 
Many lab-scale studies on the UV-C processing of milk revealed the efficiency of the process

103 (Choudhary et al., 2011; Bandla et al., 2012; Gunter-ward et al., 2018; Ansari et al., 2019). Still,

104 the major challenges at the pilot scale are limited light penetration and mass transfer (Sizer and

105 Balasubramanian, 1999) and fluence delivery per single pass. Milk is an opaque fluid with high

106 absorption as well as scattering coefficient due to the presence of lipids, proteins and vitamins.

107 UV light is absorbed by these micro and macro nutrients and creates UV gradients (Walstra and 108 Jenness, 1984). Some studies reported that the major problem of UV-C processing is oxidation of 109 fats and off-flavors (Bekbölet, 1990; Matak et al., 2005, 2007). However, the use of an efficient 110 reactor design can improve mass transfer and mix the bulk field homogenously overcoming those 111 challenges, delivering a uniform UV fluence (Koutchma, 2009). It is quite evident in the literature 112 that Dean flow reactor is an efficient design where additional turbulence is generated when fluid 113 passes through the coiled tube (Dean, 1927; Gopisetty et al., 2018; Vashisht et al., 2021). This is

114 known as the Dean effect, and it is produced by the curvature radius between the inner and outer 115 boundary layer (Dean, 1927). In our previous study we used a simulated fluid and scientifically 116 proved that the Dean flow UV reactor distributes the fluence homogeneously demonstrated by the 117 linear microbial inactivation kinetics (Vashisht et al., 2021). In reactor engineering, it is crucial to 118 ensure that all the fluid particles receive the UV fluence within the acceptable limit i.e. minimal 119 product damage and efficient microbial inactivation. An understanding of the fluid mechanical and 120 flow properties is extremely important. Herein, we will evaluate the peroxidation and volatiles of 121 WM, confirming the UV fluence (pasteurization equivalent dose). We hypothesize that effective 122 fluence delivery in the system can inactivate the pathogens and preserve the quality of the product.

123 The objectives of the present study are i) validation of the pilot-scale Dean flow UV system using 
124 biodosimetry approach, ii) evaluation of the microbial inactivation kinetics, iii) assessment of the

125 volatile profile and lipid peroxidation of the UV irradiated whole milk.

126

127

128

129

130

131

132

133

134

135

136

137

138

139

140

141

142

143

144

145

146

\section{Materials and Methods}

2.1. Bacteriophage and endospores propagation

T1UV bacteriophage and Bacillus cereus ATCC 14579 endospores were used in this study. T1

UV culture (@10 10 pfu/mL) was purchased from GAP EnviroMicrobial Services Limited, London, ON, Canada and Bacillus cereus ATCC 14579 was obtained from American Type Culture Collection (ATCC) center (Manassas, VA). Culturing of endospores was conducting using a Bacto Brain Heart Infusion Broth (BHI, Beckton, Dickinson, Franklin Lakes, NJ) as a growth medium, incubation was done at $37^{\circ} \mathrm{C}$ with aeration at $180 \mathrm{rpm}$. Nutrient-rich, a chemically defined medium known as Mineral Salts Medium (MSM) was used for sporulation. $20 \mathrm{~mL}$ of overnight grown culture was inoculated in $200 \mathrm{~mL}$ of MSM in $1 \mathrm{~L}$ of the flask. Incubation was be done at $30{ }^{\circ} \mathrm{C}$ with aeration at $180 \mathrm{rpm}$ for 3 days. Dormant spores were purified by suspending the pellets in 20\% Nycodenz (VWR, Atlanta, GA) followed by 50\% Nycodenz density gradient centrifugation at $14000 \mathrm{~g}$ for 45 minutes. Enumeration was done using a standard plate count method.

\subsection{Optical properties}

Optical properties (absorbance and reduced scattering) of the WM were evaluated at $254 \mathrm{~nm}$ by using a double beam spectrophotometer connected to a 6-inch integrating sphere. Inverse addling doubling technique was used to quantify the absorption coefficient, scattering coefficient, base-e. A series of thin quartz cuvettes were used to achieve a light transmission between 10 to 14\%. A MS-DOS based code was run to separate the absorption coefficient and reduced scattering coefficients. Light absorption and reflection were accounted for in the calculations.

$$
\text { Transmittance }\left(\frac{\%}{\mathrm{~cm}}\right)=\left(10^{-\mathrm{A}}\right) \times 100
$$


147 where A stands for the absorbance (base 10) of the sample at $254 \mathrm{~nm}$ for a $1 \mathrm{~cm}$ path length.pH of

148 the product was measured by using a pH meter (Jenway, Cole Palmer, OSA, UK). All the 149 measurements were taken in triplicate to reduce error.

150 2.3. Organism sensitivity test

Bacillus cereus ATCC 14,579 and T1UV phage were evaluated for $\mathrm{D}_{10}$ values (dose required

152 for $90 \%$ inactivation or $10 \%$ survival). Microorganisms were inoculated separately (@ $10^{6}-10^{7}$

$153 \mathrm{CFU} / \mathrm{mL}$ or PFU/mL) in whole milk. The absorption coefficient of the final solution was measured

154 using the UV-Vis. spectrophotometer (Thermo Scientific, Genesys 10S, Milwaukee, WI, US).

155 Known UV fluence were delivered $\left(3,6\right.$, and $\left.9 \mathrm{~mJ} / \mathrm{cm}^{2}\right)$ for both the microorganisms (Bolton and

156 Linden, 2003). $5 \mathrm{~mL}$ of sample was exposed to UV using a Collimated Beam Apparatus (Trojan

157 Technologies, London, ON, Canada), which contains a $25 \mathrm{~W}$ low-pressure mercury lamp. The

158 suspension was stirred during irradiation using a magnetic stirrer to ensure equal UV volatil to all

159 microorganisms. The $\mathrm{D}_{10}$ value was evaluated using the LINEST function of Microsoft Excel

160 between the UV fluence delivered, and the log inactivation obtained. All the experiments were

161 done in triplicate to reduce the error

162

2.4. UV- C Treatment

163

WM was exposed to UV-C light using the Dean flow UV system (Fig. 1). The system is a

164 continuous UV reactor, consisting of a 500W low-pressure mercury lamp protected with stainless

165 steel cylindrical blocker, a cooling fan, and a food-grade FEP (Fluorinated Ethylene Propylene)

166 tube. The tube length is $26 \mathrm{~m}$ with an inner diameter $\left(\mathrm{D}_{\mathrm{i}}\right)$ of $0.64 \mathrm{~cm}$, an outer diameter $\left(\mathrm{D}_{\mathrm{o}}\right)$ of

$1670.74 \mathrm{~cm}$, a wall thickness of $0.5 \mathrm{~mm}$. The tube was wrapped around the centrally positioned lamp

168 in a serpentine path. The diameter of the coil $\left(D_{c}\right)$ was $12.7 \mathrm{~cm}$. The tubing was carefully

169 engineered to have significant curves (bends) to induce mixing. The system also included a 4-20 
170

171

172

173

174

175

176

177

178

179

180

181

182

183

184

185

186

187

$188 \quad \mathrm{R}_{\mathrm{e}}=\frac{\rho \mathrm{VD}}{\mu}$

$\mathrm{mA}$ current loop receiver and an indicator for output power lamp display. The electric supply of $220 \mathrm{~V}$ (single phase), $60 \mathrm{~Hz}$ was used. The irradiance at the surface of the FEP tube was 22 $\mathrm{mW} / \mathrm{cm}^{2}$, measured using an International Light Technologies (Peabody, MA) IL-1700 radiometer with a SED 240 detector fitted with a NS254 filter. Transmittance (UVT\%) of FEP tube was 65\%, measured using a UV-Visible Spectrophotometer (Thermo Scientific, Genesys 10S, Milwaukee, WI, US). Therefore, the calculated UV intensity at the surface of the fluid was $14.3 \mathrm{~mW} / \mathrm{cm}^{2}$. The total reactor volume was $0.80 \mathrm{~L}$. The system was connected to an inlet, outlet, and a rinse tank (20 L each). The output power at $254 \mathrm{~nm}$ was approximately 220 Watts at $254 \mathrm{~nm}$. WM was treated at a flow rate of $0.75,1.5$, and $3 \mathrm{~L} / \mathrm{min}$ (equivalent to $11.88,23.77,47.55 \mathrm{gph}$, respectively). The flowrate was controlled by Watson Marlow 730U peristaltic pump (Watson Marlow, Charlotte, NC, US). The pump was validated by using a bucket test in which time to collect a known volume of the fluid was estimated. CIP was done before starting the experiment as well as at the end. All experiments were conducted in triplicated to reduce random error. Dean number (De) evaluated as a function of Reynolds number $(\mathrm{Re})$ and the geometric parameters D and Dc, which stands for the hydraulic diameter of the tube $(\mathrm{m})$ and diameter of the coil (m), respectively (Gopisetty et al., 2018, 2019). The following equation was used:

$D_{e}=R_{e}\left(\frac{\sqrt{D}}{D_{c}}\right)$

where $\rho$ denotes the fluid density, $\mu$ denotes the dynamic viscosity, $\mathrm{V}$ is the fluid velocity, and $\mathrm{D}$ denotes the diameter of the tube. The $\mathrm{R}_{\mathrm{e}}$ of $<2100$ represents laminar flow pattern, $\mathrm{R}_{\mathrm{e}}$ between 2100-4000 shows transient flow conditions, and $R_{e}$ of $>4000$ means turbulent flow conditions

192 (Bandla et al., 2012; Pendyala et al., 2021; Vashisht et al., 2021). The residence time (RT) was 64, 
19332 and 16 seconds for $0.75 \mathrm{~L} / \mathrm{min}$. (11.88 gph), $1.5 \mathrm{~L} / \mathrm{min}$. (23.77 gph) and $3 \mathrm{~L} / \mathrm{min}$. (47.55 gph)

194 respectively, which was evaluated by using the following equation:

$195 \quad \mathrm{RT}=\frac{\mathrm{V}}{\mathrm{Q}}$

196 Where Vis the volume (L); Q is the flow rate (L/min) Average flow velocity (vf) (m/sec.) was

197 evaluated by using the following equation:

$198 \quad V_{\mathrm{f}}=\frac{\mathrm{Q}}{\pi \mathrm{r}^{3} \times 60 \times 10^{3}}$

199 Q is the flow rate of fluid in $\mathrm{L} / \mathrm{min}$. $\mathrm{r}$ is the tube's radius in $\mathrm{m}$.

200

201

202

203

204

205

206

207

208

209

210

211

212

213

2.5. Determination of volatiles using electronic nose

Volatiles were evaluated by using an electronic nose (Heracles II, Alpha MOS, Toulouse, France). It consists of two columns working in parallel mode: a non-polar column (MXT5: 5\% diphenyl, 95\% methylpolysiloxane, $10 \mathrm{~m}$ length and $180 \mu \mathrm{m}$ diameter). The volatiles profile of treated samples (at 60 and $120 \mathrm{~mJ} / \mathrm{cm}^{2}$ of fluence) was compared with controlled (untreated) samples. $20 \mathrm{~mL}$ of vials were filled with $10 \mathrm{~mL}$ of the sample followed by sealing with septa screw cap using a crimper. The vials were equilibrated for 200 seconds at $50{ }^{\circ} \mathrm{C}$ in agitation chamber. Autosampler was used to inject the generated headspace aroma into the electronic nose column at a flow rate of $270 \mu \mathrm{L} / \mathrm{s}$. The column temperature program was $40^{\circ} \mathrm{C}(1 \mathrm{~min})-2{ }^{\circ} \mathrm{C} \mathrm{min}^{-1}-200{ }^{\circ} \mathrm{C}$ ( $3 \mathrm{~min}$ ). The temperature of injector and detector was set at $180^{\circ} \mathrm{C}$ and $220^{\circ} \mathrm{C}$, respectively. The chromatograms were obtained using Flame ionization detector (FID) and individual volatile profile including Kovats index, retention time and sensory description was evaluated by using AromaChemBase software. The analysis was done by using Alpha Soft (Alpha Soft version 3.0.0, Toulouse, France). All the samples were evaluated in triplicate to reduce error and all the values were mentioned in terms of relative area. 
$$
\mathrm{E}_{\mathrm{EO}}=\frac{\mathrm{P}_{\mathrm{UV}}}{\mathrm{F} \times \log \frac{\mathrm{Co}}{\mathrm{Ct}}}
$$

\subsection{Determination of lipid peroxidation}

Lipid peroxidation value was evaluated by a standard curve method using spectrophotometer. According, to Matak et al. (2007) value is measured in terms of MDA (malondialdehyde) and other reactive substance so standards of 50, 25, 12.5, 6.25, 3.125 $\mu \mathrm{M}$ concentrations were prepared using MDA. $1 \mathrm{~mL}$ of irradiated whole milk was mixed and vortexed with $7 \mathrm{~mL}$ of $1 \%$ phosphoric acid followed by the addition of $2 \mathrm{~mL}$ of $42 \mathrm{mmol} / \mathrm{L} \mathrm{TBA}$ (thiobarbituric acid). The solution was heated at $100^{\circ} \mathrm{C}$ for 60 minutes followed by cooling it down (by keeping on ice). The color was changed to pink, where the intensity was dependent upon the extent of lipid peroxidation. $4 \mathrm{~mL}$ of solution was added to the $4 \mathrm{~mL}$ of 1:12 mixture of $2 \mathrm{~mol} / \mathrm{L}$ sodium hydroxide and methanol, it was vortex mixed for 10 seconds followed by centrifugation at $13000 \mathrm{~g}$ for 3 minutes. Supernatant was evaluated for absorbance at $532 \mathrm{~nm}$ using a UV-Vis spectrophotometer (Thermo Scientific, Genesys 10S, Milwaukee, WI, US) calibrated against blank.

\subsection{Electrical energy per order $\left(\mathrm{E}_{\mathrm{EO}}\right)$}

EEO was estimated to measure the kilowatt-hours of energy required to reduce the microbial population by one $\log$ (Bolton, 2010). This term is commonly used to assess electrical energy efficiency (Ward et al., 2019). EEO value depends upon the nature of fluid under processing and the geometry of the reactor (Pendyala et al., 2021). Evaluation was done by using the equation given by Ward et al. (2019).

where $\mathrm{P}_{\mathrm{UV}}$ refers to the power of the electric lamp or total energy of the lamp and power supply (kW), F stands for volumetric flow rate $\left(\mathrm{m}^{3} / \mathrm{h}\right.$.), and Co and Ct stand for initial and final microbial concentration, respectively.

2.8. Statistical Analysis 
All the treatments were conducted in replicates where each sample was independent and randomly assigned. All the values are reported as mean \pm std. deviation. For evaluation of effect of numerous treatments on REF, inactivation kinetics, lipid peroxidation and volatiles profile oneway ANOVA along with the Tukey HSD (honestly significant difference) at $p<0.05$ significance

242 level.

243

244

245

246

247

248

249

250

251

252

253

254

255

256

257

258

259

260

261

\section{Result and Discussion}

\subsection{Optical properties of test fluid}

Optical properties of WM are illustrated in Table 1. The absorption and reduced scattering coefficient were measured as $23.7 \pm 0.3 \mathrm{~cm}^{-1}$ (transmittance $-2.5 \mathrm{E}-22 \% / \mathrm{cm}$ ) and $42.3 \pm 0.5 \mathrm{~cm}^{-1}$ respectively, with $12 \%$ reflectance. The $\mathrm{pH}$ and fat content of the WM was $6.73 \pm 0.17$ and 3.27 $\%$, respectively. Previous studies evaluated the absorption coefficient of whole milk without separating the reduced scattering coefficient and reported significantly higher values, $220 \mathrm{~cm}^{-1}$ (Choudhary et al., 2011), $326 \pm 1.5 \mathrm{~cm}^{-1}$ (Ansari et al., 2019). Optical properties clearly show the opaque nature of the test fluid. WM significantly absorbs and scatters the UV photons. Suspended particles are mainly responsible for attenuation of UV light via scattering effect (Gunter-ward et al., 2018). If the product particles are larger than the UV wavelength then it leads to the forward scattering with amplified back scattering effect (Koutchma, 2009). Our results demonstrate high scattering effect of WM, due to fat globules and proteins (micellar casein) as reported in the literature (Gunter-ward et al., 2018; Ward et al., 2019). There could be a minor scattering effect due to dissolved minerals and sugar (lactose), however it can be ignored because their proportionate size is lesser than the fat and protein components (Gastélum-Barrios et al., 2020).

\subsection{Design and Development of dean flow reactor}

Many literature studies used circular path coiled tube dean flow UV systems to evaluate microbial inactivation in milk (Choudhary et al., 2011; Bandla et al., 2012; Ansari et al., 2019). 
262 To improve the Dean forces, in our previous proof-of-concept study we designed and developed

263 pilot scale serpentine path coiled Dean flow UV system and evaluated its microbial inactivation

264 efficiency. Previously, we irradiated fluids with absorption coefficient ranging from 6.5 to $17 \mathrm{~cm}^{-}$

$265{ }^{1}$ at commercial flow rates (Vashisht et al., 2021) and evaluated the system performance. In the

266 current study, the system was challenged against a highly opaque fluid such a WM with an

267 absorption coefficient of $23.7 \mathrm{~cm}^{-1}$. The initial design of the system consisted of a Teflon tubing

268 (45\% UV transmission) of $1 \mathrm{~cm}$ path length, $20 \mathrm{~m}$ total length and $18 \mathrm{~cm}$ coil diameter (Vashisht

269 et al., 2021). The reactor system was modified where FEP tubing (65\% UV transmission) was used

270 to have high transmittivity. Tube length was increased to $26 \mathrm{~m}$ to increase the residence time and

271 UV fluence/pass. The optical thickness of the fluid was reduced to $0.64 \mathrm{~cm}$. This will allow higher

272 penetration of photons in the bulk fluid. The coil diameter was reduced to $12.7 \mathrm{~cm}$ to increase the

273 Dean effect (as Dean number is inversely proportional to coil diameter). The ratio of D to Dc

274 (where D stands for inner diameter of tubing $(0.64 \mathrm{~cm})$, and Dc stands for the diameter of coil

$275(12.7 \mathrm{~cm}))$ of the designed reactor was $0.050(0.64 / 12.7)$, which was in the range of $0.03-0.10$

276 demonstrating the initiation of Dean flow vortices during the experiments (Koutchma, 2009).

277 Bandla et al. (2012) used Reynolds number as a parameter of turbulence but missed to evaluate

278 the Dean number. This number is a significant parameter as it generates the additional turbulence

279 hence the efficient mixing conditions (Dean 1927, Gopisetty et al., 2018, 2019). The evaluated

280 Reynolds and Dean number for each flow rate was in the range of 2890-11562 and 648-2595,

281 respectively (Table 2). This data revealed that the experiments were conducted at transient to fully

282 turbulent conditions to provide efficient mass transfer (Dean, 1927; Patras et al., 2020). Turbulent

283 flow conditions deliver higher velocity to the particles as compared to the mean velocity of

284 individual particles providing efficient UV fluence distribution (Koutchma, 2009). Volume 
285

286

287

288

289

290

291

292

293

294

295

296

297

298

299

300

301

302

303

304

305

306

307 average UV intensity depends on the relative positions of the particle and the UV lamps orientation. The UV fluence received by the micro-organisms depends on two main factors: the trajectories through the system and the REF rate (Vashisht et al., 2021). The incident radiation rate is dependent on the positions of the UV lamps within the UV system.

\subsection{UV fluence validation at experimental flow rates}

Biodosimetry study was conducted using B. cereus endospores to quantify delivered UV fluence. The $\mathrm{D}_{10}$ value of $B$. cereus endospore was quantified using a standard collimated beam system as $8.91 \pm 0.07 \mathrm{~mJ} / \mathrm{cm}^{2}$, it was within the range as reported in the literature (Gopisetty et al., 2018; Pendyala et al., 2019, 2020, 2021). WM was inoculated with B. cereus $\left(10^{7} \mathrm{cfu} / \mathrm{mL}\right)$ and it was passed through the UV systemlight at flow-rates of $0.75 \mathrm{~L} / \mathrm{min} .(11.88 \mathrm{gph}), 1.5 \mathrm{~L} / \mathrm{min}$. (23.77 gph) and $3 \mathrm{~L} / \mathrm{min}$. (47.55 gph). REF was evaluated as a product of $\mathrm{D}_{10}$ value and log reduction $\left(\log \mathrm{N}_{0}-\mathrm{N}\right)$. Total REF was $26 \pm 1.07,14.5 \pm 0.53$ and $10 \pm 0.27 \mathrm{~mJ} / \mathrm{cm}^{2}$ at $11.88,23.77$ and 47.55 gph of flow rate, respectively. It was observed that with the increase in flow rate, total REF was significantly reduced due to lower hydraulic retention times (Fig. 2a). In contrast, the REF rate (REF per sec.) was observed to be increase with the increase in flow rate attributed to the increase in turbulence and Dean forces intensity as demonstrated by the increased Reynolds and Dean number (Fig. 2b). Similar trends were reported by previous authors (Gunter-Ward et al., 2018; Ansari et al., 2019; Vashisht et al., 2021). According to Vashisht et al. (2021) Dean number plays a pivotal role in UV fluence distribution while the residence time directs the total REF for the inactivation of microbes hence a balance needs to be maintained between these process parameters.

Herein, REF rate can be a useful factor for the determination of system's performance in terms of fluence distribution which is critical at commercial level. At $47.55 \mathrm{gph}$ flow rate, the REF rate was 1.54 and 1.38 times efficient than the 11.88 and $23.77 \mathrm{gph}$ of flow rate. UV-C systems are suitable 
308

309

310

311

312

for the treatment of opaque liquids when efficient mixing conditions that can surpass the potent intensity gradient and ensure effective fluence distribution (Vashisht et al., 2021). Inefficient mixing conditions will significantly affect the UV system performance and will result in non-linear inactivation kinetics of the target pathogen (Atilgan, 2013; Crook et al., 2015). Completing understanding of the UV system performance, knowledge of optical properties of the test fluids will allow accurate sizing of UV systems.

\subsection{Microbial Inactivation studies}

Since better system performance was observed at higher flow rate, microbial inactivation studies were conducted at a flowrate of 47.55 gph using B. cereus endospores and T1UV virus particles (selected as a surrogate to Salmonella, Listeria and Cronobacter). Selection of pertinent microorganism is of utmost importance during validation studies (Patras et al., 2020). B. cereus endospores are most common pertinent bacterial spores present in milk and causes food safety and spoilage issues (Choudhary et al., 2011, Gunter-Ward et al., 2018; Patras et al., 2020) while Salmonella \& Listeria are the pertinent vegetative microorganisms in milk (Patras et al., 2020). The $\mathrm{D}_{10}$ value of T1UV phage is similar to Salmonella and Listeria and therefore used in this research study. $0.91 \pm 0.15$ and $2.14 \pm 0.19 \log$ reduction per pass $\left(\mathrm{R}^{2}>0.99, \mathrm{p}<0.05\right)$ was observed for B. cereus and T1UV phage, respectively (Fig. 3a and 3b). Linear trend demonstrates uniform REF delivery during each pass. The kinetics of the UV inactivation are widely assumed for a first-order reactions with respect to the REF. The typical UV response curve can be represented in two ways: a log survival curve and a log inactivation curve

It is quite evident if the system is not efficient and does not provide good mixing conditions, then the desired UV fluence will not be delivered to the microbes which may result in lower inactivation rate at higher UV fluence (Bhullar et al., 2019) and tail may be observed in inactivation 
curve. For instance, Makarapong et al. (2020) reported 4.7 and 4.6 log reduction of total microbial count in WM treated with 98 and $110 \mathrm{~mJ} / \mathrm{cm}^{2}$ of UV fluence. In our studies total log reduction of B. cereus and T1 UV phage were $2.75 \pm 0.01$ and $4.29 \pm 0.09$ after three and two passes, respectively. Previous Dean concept studies reported a significant log reduction of pathogenic microbes in dairy products. Ansari et al. (2019) reported B. cereus endospores log reduction of 6, 2.90 and 1.1 in skim, cow and bovine milk, respectively where UV-C processing was used as hurdle technology. Bandla et al. (2012), reported 2.3 log reduction of standard plate count in raw cow milk given a UV-C fluence of $16.82 \mathrm{~mJ} / \mathrm{cm}^{2}$. Matak et al. (2005) reported 5-log reduction of Listeria monocytogenes in goat milk given a UV-C fluence of $15.8 \pm 1.6 \mathrm{~mJ} / \mathrm{cm}^{2}$ but the inactivation kinetics reported was non-linear which demonstrates that author failed to achieve efficient mixing conditions. Crook et al. (2015) used thin film reactor and reported 5-log reduction of Listeria monocytogenes and Staphylococcus aureus in WM, but the fluence was reported in J/L which is disparate to the commonly used standard unit i.e., $\mathrm{mJ} / \mathrm{cm}^{2}$. In our previous studies we introduced the concept of Pasteurization and Sterilization Equivalent Dose referred to the fluence required for $5 \log$ reduction of $S$. Typhimurium and $6 \log$ reduction of $B$. cereus endospores, respectively (Vashisht et al., 2021). Therefore, in our studies at 47.55 gph of flow rate, 3 and 7 passes are sufficient to provide a pasteurization and sterilization equivalent dose, respectively while another approach could be scaling up and increasing the length of tubing of the present system to increase the residence time and hence the delivered fluence per pass.

\subsection{Lipid peroxidation}

Milk consists of photosensitizers compounds such as riboflavin which can cause lipid peroxidation during UV-C light exposures and can deteriorate the quality and limits the shelf life of the dairy products (Bekbolet, 1990). The product of these reactions are hydroperoxides that can 
354

355

356

357

358

359

360

361

362

363

364

365

366

367

368

369

370

371

372

373

374 375 higher for the pasteurization equivalent dose reported in this study.

decompose and form free-radicals which further causes auto oxidation and formation of offflavoring compounds (Bekbolet, 1990). The oxidation reactions are prompt and usually take place when milk is exposed to metal surface or light (van Aardt et al., 2005). According to Cadwallader and Howard, 1998 autoxidation and light induces oxidation of unsaturated fatty acids of milk are primarily responsible for the origination of off flavor and reduction in nutritive compounds like ascorbic acid and riboflavin. Literature studies reported that the extent of lipid peroxidation is directly proportional to riboflavin content, and it is significantly affected by the exposure to UV light photons (van Aardt et al., 2005). In our studies the pertinent microorganism was B. cereus. Hence, sterilization equivalent dose for B. cereus was $53.46 \mathrm{~mJ} / \mathrm{cm}^{2}\left(6 \times 8.91 \mathrm{~mJ} / \mathrm{cm}^{2}\right)($ Vashisht et al., 2021). Therefore $60 \mathrm{~mJ} / \mathrm{cm}^{2}, 120 \mathrm{~mJ} / \mathrm{cm}^{2}$ and $180 \mathrm{~mJ} / \mathrm{cm}^{2}$ of $\mathrm{UV}$ fluence were selected for lipid peroxidation studies. The temperature during the UV light exposures processing was maintained at $4{ }^{\circ} \mathrm{C}$ to nullify the effect of lipase activity on fatty acids in WM (Deeth and FitzGerald, 1995). Fig. 4 demonstrates the increase of lipid peroxidation in a polynomial trend (2 order equation) with the increase in the delivered UV fluence. Controlled samples had positive MDA value $(0.110 \pm 0.002 \mu \mathrm{M})$, which shows that the lipid peroxidation was initially present in the WM. At UV-C fluence of 60,120 and $180 \mathrm{~mJ} / \mathrm{cm}^{2}$, MDA concentration was $0.114 \pm 0.004,0.138 \pm$ 0.005 , and $0.168 \pm 0.002 \mu \mathrm{M}$, respectively. Fig $4 \mathrm{~b}$ demonstrates that there was no significant difference $(\mathrm{p}<0.05)$ between the MDA concentration of the controlled samples and the samples treated with UV-C fluence of $60 \mathrm{~mJ} / \mathrm{cm}^{2}$, enough to inactivate 6.73-log of B. cereus and 12.58- $\log$ of T1 phage. Makarapong et al. (2020) reported a significant lipid peroxidation in WM samples treated with 98 and $110 \mathrm{~mJ} / \mathrm{cm}^{2}$ of fluence. However, the evaluated fluence was significantly

376 3.6. Volatiles Profile 
Table 3 represents the volatiles profile of the untreated and irradiated WM samples. The

378 irradiated samples were exposed to UV fluence of 60 and $120 \mathrm{~mJ} / \mathrm{cm}^{2}$ fluence prior to the

379 evaluation of their volatiles profile. Overall, aldehyde concentration was not significantly $(\mathrm{p}>$

380 0.05) affected UV irradiated samples. Primary aldehydes present in untreated samples were 2-

381 methylpropanal, butanal, and acetaldehyde, while in irradiated samples, pentanal, hexanal, and

382 butanal were majorly present. According to Kim and Morr (1996), hexanal can originally be

383 present in the milk while its formation and overall concentration can be increased by the lipid

384 peroxidation caused by the UV light treatment. Similar results were observed in our studies. There

was a significant difference $(\mathrm{p}>0.05)$ in overall alcohol concentration in irradiated samples where

1-propanol, n-butanol, and 1-hexanol were major contributors. Among ketones, butane-2,3-dione

was majorly present in untreated samples, and its concentration relatively decreased in both

irradiated samples (Vazquez-Landaverde et al., 2006). Pereda et al. (2008) reported only one

carboxylic acid, i.e., hexanoic acid, in their study because of their less volatility and inefficiency

of the system to extract these compounds. In our experiment, we detected seven of them where the observed which may be the consequences of light reactions. 
400

401

402

403

404

405

406

407

408

409

410

411

412

413

414

415

416

417 Further studies revealed that at $60 \mathrm{~mJ} / \mathrm{cm}^{2}$ no significant effect on lipid peroxidation and volatiles

418

419

420

421

lower $\mathrm{D}_{10}$ value. Lower $\mathrm{E}_{\mathrm{EO}}$ value demonstrates the higher efficiency of the system. Since each microorganism has specific UV sensitivity ( $\mathrm{D}_{10}$ value), $\mathrm{E}_{\mathrm{EO}}$ value significantly varies with geometric parameters, design of reactor, processing conditions and nature of fluid under testing (Pendyala et al., 2021, Vashisht et al., 2021). EEO value of B. cereus was evaluated for each flow rate (Table 4), where it was observed to be decreasing with the increased flow rate attributed to uniform distribution of fluence because of increased turbulence and Dean effect resulted in increased inactivation kinetics. This proves the efficiency of system was more at highest flow rate (47.88 gph) as compared to the lowest one (11.88 gph). At high flow rate two or more reactors are recommended in a series to increase the residence time and hence to deliver the targeted UV fluence. Therefore, a balance needs to be maintained between the chosen flow rate and number of reactors required in a series.

\section{Conclusion}

A Dean flow UV system was evaluated and experimentally studied using WM as a test fluid due to its high scattering coefficients. Biodosimetry studies were conducted and test results showed that 47.55 gph of flow was the most efficient experimental flow rate for the coiled geometry. Linear inactivation trends were observed for B. cereus and T1UV phage demonstrating equivalent fluence during each pass. Lower $\mathrm{E}_{\mathrm{EO}}$ value also signifies the higher electrical efficiency of the system. profile was observed. The reported fluence is enough to inactivate $7.18 \log$ population of $B$. cereus and $12.57 \mathrm{log}$ of T1UV phage. Therefore, it can be concluded that commercial scale UV-C processing of opaque fluids like WM is feasible using an efficient reactor design such as Dean flow system. Further studies on sensory quality of UV exposed WM is warranted in the future. 


\section{Acknowledgments}

423 This project was funded under the Agriculture and Food Research Initiative (Food Safety

424 Challenge Area), USDA, Award numbers; 2018-38821-27732, and 2019-69015-29233. The

425 authors would like to thank Trojan Technologies for providing valuable guidance in this project.

426 Note: There are no conflicts to declare.

\section{5. References}

428 Ansari, J. A., Ismail, M., \& Farid, M. (2019). Investigate the efficacy of UV pretreatment on

429 thermal inactivation of Bacillus subtilis spores in different types of milk. Innovative Food Science 430 \& Emerging Technologies, 52, 387-393.

431 Atılgan, M. R. (2013). Design of a continuous flow UV reactor for opaque liquid foods by using 432 computational fluid dynamics (CFD).

433 Bandla, S., Choudhary, R., Watson, D. G., \& Haddock, J. (2012). UV-C treatment of soymilk in 434 coiled tube UV reactors for inactivation of Escherichia coli W1485 and Bacillus cereus 435 endospores. LWT-food Science and Technology, 46(1), 71-76.

436 Bekbölet, M. (1990). Light effects on food. Journal of food protection, 53(5), 430-440.

437 Bermúdez-Aguirre, D., Corradini, M. G., Mawson, R., \& Barbosa-Cánovas, G. V. (2009). 438 Modeling the inactivation of Listeria innocua in raw whole milk treated under thermo439 sonication. Innovative Food Science \& Emerging Technologies, 10(2), 172-178.

440 Bhullar, M. S., Patras, A., Kilonzo-Nthenge, A., Pokharel, B., \& Sasges, M. (2019). Ultraviolet 441 inactivation of bacteria and model viruses in coconut water using a collimated beam system. Food $442 \quad$ Science and Technology International, 25(7), 562-572 
443 Bilbao-Sáinz, C., Younce, F. L., Rasco, B., \& Clark, S. (2009). Protease stability in bovine milk 444 under combined thermal-high hydrostatic pressure treatment. Innovative food science \& emerging 445 technologies, 10(3), 314-320.

446 Bogahawaththa, D., Buckow, R., Chandrapala, J., \& Vasiljevic, T. (2018). Comparison between 447 thermal pasteurization and high pressure processing of bovine skim milk in relation to denaturation 448 and immunogenicity of native milk proteins. Innovative Food Science \& Emerging 449 Technologies, 47, 301-308.

450 Bolton, J. R. (2010). Ultraviolet Applications Handbook ICC Lifelong Learn. Inc., Edmonton, AB, 451 Canada.

452 Bolton, J. R., \& Linden, K. G. (2003). Standardization of methods for fluence (UV dose) 453 determination in bench-scale UV experiments. Journal of environmental engineering, 129(3), $454 \quad 209-215$.

455 Braun- Fahrländer, C., \& Von Mutius, E. (2011). Can farm milk consumption prevent allergic 456 diseases? Clinical \& Experimental Allergy, 41(1), 29-35.

457 Buchin, S., Delague, V., Duboz, G., Berdague, J. L., Beuvier, E., Pochet, S., \& Grappin, R. (1998). 458 Influence of pasteurization and fat composition of milk on the volatile compounds and flavor 459 characteristics of a semi-hard cheese. Journal of Dairy Science, 81(12), 3097-3108.

460 Cadwallader, K. R., \& Howard, C. L. (1998). Analysis of aroma-active components of light461 activated milk.

462 Cappozzo, J. C., Koutchma, T., \& Barnes, G. (2015). Chemical characterization of milk after 463 treatment with thermal (HTST and UHT) and nonthermal (turbulent flow ultraviolet) processing 464 technologies. Journal of Dairy Science, 98(8), 5068-5079. 
465 Choudhary, R., \& Bandla, S. (2012). Ultraviolet pasteurization for food industry. International 466 Journal of Food Science and Nutrition Engineering, 2(1), 12-15.

467 Choudhary, R., Bandla, S., Watson, D. G., Haddock, J., Abughazaleh, A., \& Bhattacharya, B. 468 (2011). Performance of coiled tube ultraviolet reactors to inactivate Escherichia coli W1485 and 469 Bacillus cereus endospores in raw cow milk and commercially processed skimmed cow 470 milk. Journal of food engineering, 107(1), 14-20.

471 Corrales, M., de Souza, P. M., Stahl, M. R., \& Fernández, A. (2012). Effects of the 472 decontamination of a fresh tiger nuts' milk beverage (horchata) with short wave ultraviolet 473 treatments (UV-C) on quality attributes. Innovative Food Science \& Emerging Technologies, 13, $474 \quad 163-168$.

475 Cosentino, S., Mulargia, A. F., Pisano, B., Tuveri, P., \& Palmas, F. (1997). Incidence and 476 biochemical characteristics of Bacillus flora in Sardinian dairy products. International journal of 477 food microbiology, 38(2-3), 235-238.

478 Crielly, E. M., Logan, N. A., \& Anderton, A. (1994). Studies on the Bacillus flora of milk and 479 milk products. Journal of applied bacteriology, 77(3), 256-263.

480 Crook, J. A., Rossitto, P. V., Parko, J., Koutchma, T., \& Cullor, J. S. (2015). Efficacy of ultraviolet 481 (UV-C) light in a thin-film turbulent flow for the reduction of milkborne pathogens. Foodborne 482 pathogens and disease, 12(6), 506-513.

483 Cullor, J. (2011). Effects of ultraviolet light treatment on milk and microbiological quality. 484 In Proc. 3rd Int. Symp. Mastitis and Milk Quality, St. Louis, MO. National Mastitis Council, 485 Madison, WI. 
Dean, W. R. (1927). XVI. Note on the motion of fluid in a curved pipe. The London, Edinburgh, and Dublin Philosophical Magazine and Journal of Science, 4(20), 208-223.

Deeth, H. C., Fitz-Gerald, C. H., \& Fox, P. F. (1995). Advanced dairy chemistry.

EFSA, 2016. Safety of UV-treated milk as a novel food pursuant to Regulation (EC) No 258/97.

Feng, M., Ghafoor, K., Seo, B., Yang, K., \& Park, J. (2013). Effects of ultraviolet-C treatment in juice. Innovative Food Science \& Emerging Technologies, 19, 133-139.

497 Garcia-Amezquita, L. E., Primo-Mora, A. R., Barbosa-Cánovas, G. V., \& Sepulveda, D. R. (2009). Effect of nonthermal technologies on the native size distribution of fat globules in bovine cheesemaking milk. Innovative Food Science \& Emerging Technologies, 10(4), 491-494.

503 Gopisetty, V. V. S., Patras, A., Kilonzo-Nthenge, A., Yannam, S., Bansode, R. R., Sasges, M., ... 504 \& Xiao, H. (2018). Impact of UV-C irradiation on the quality, safety, and cytotoxicity of cranberry505 flavored water using a novel continuous flow UV system. LWT, 95, 230-239. 
506 Gopisetty, V. V. S., Patras, A., Pendyala, B., Kilonzo-Nthenge, A., Ravi, R., Pokharel, B., ... \&

507 Sasges, M. (2019). UV-C irradiation as an alternative treatment technique: Study of its effect on 508 microbial inactivation, cytotoxicity, and sensory properties in cranberry-flavored 509 water. Innovative Food Science \& Emerging Technologies, 52, 66-74.

510 Griffiths, M. W. (1992). Bacillus cereus in liquid milk and other milk products. Bull. Int. Dairy 511 Fed., 275, 36-38.

512 Gunter- Ward, D. M., Patras, A., S. Bhullar, M., Kilonzo- Nthenge, A., Pokharel, B., \& Sasges, 513 M. (2018). Efficacy of ultraviolet (UV- C) light in reducing foodborne pathogens and model 514 viruses in skim milk. Journal of Food Processing and Preservation, 42(2), e13485.

515 Islam, M. S., Patras, A., Pokharel, B., Wu, Y., Vergne, M. J., Shade, L., ... \& Sasges, M. (2016).

516 UV-C irradiation as an alternative disinfection technique: Study of its effect on polyphenols and 517 antioxidant activity of apple juice. Innovative Food Science \& Emerging Technologies, 34, 344518351.

519 Jermann, C., Koutchma, T., Margas, E., Leadley, C., \& Ros-Polski, V. (2015). Mapping trends in 520 novel and emerging food processing technologies around the world. Innovative Food Science \& 521 Emerging Technologies, 31, 14-27.

522 Keyser, M., Müller, I. A., Cilliers, F. P., Nel, W., \& Gouws, P. A. (2008). Ultraviolet radiation as 523 a non-thermal treatment for the inactivation of microorganisms in fruit juice. Innovative Food 524 Science \& Emerging Technologies, 9(3), 348-354.

525 Kim, Y. D., \& Morr, C. V. (1996). Dynamic headspace analysis of light activated flavor in 526 milk. International Dairy Journal, 6(2), 185-193. 
527 Koutchma, T. (2009). Advances in ultraviolet light technology for non-thermal processing of

528 liquid foods. Food and Bioprocess Technology, 2(2), 138-155.

529 Koutchma, T. (2018). Status of international regulations for ultraviolet treatment of foods. IUVA $530 \quad$ News, 20, 13-16.

531 Makarapong, D., Tantayanon, S., Gowanit, C., \& Inchaisri, C. (2020). Development of an 532 innovative apparatus using UV-C for controlling the number of microorganisms in raw milk after 533 milking. International Journal of Dairy Technology, 73(1), 301-305.

534 Matak, K. E., Churey, J. J., Worobo, R. W., Sumner, S. S., Hovingh, E., Hackney, C. R., \& Pierson, 535 M. D. (2005). Efficacy of UV light for the reduction of Listeria monocytogenes in goat's 536 milk. Journal of Food Protection, 68(10), 2212-2216.

537 Matak, K. E., Sumner, S. S., Duncan, S. E., Hovingh, E., Worobo, R. W., Hackney, C. R., \& 538 Pierson, M. D. (2007). Effects of ultraviolet irradiation on chemical and sensory properties of goat 539 milk. Journal of Dairy Science, 90(7), 3178-3186.

540 McGUigGAN, J. T. M., GILMOUR, A., \& LAWRENCE, L. M. (1994). Factors influencing the 541 recovery of psychrotrophic, mesophilic and thermophilic Bacillus spp from bulk raw 542 milk. International Journal of Dairy Technology, 47(4), 111-116.

543 Munir, M., Nadeem, M., Qureshi, T. M., Leong, T. S., Gamlath, C. J., Martin, G. J., \& 544 Ashokkumar, M. (2019). Effects of high pressure, microwave and ultrasound processing on 545 proteins and enzyme activity in dairy systems - A review. Innovative Food Science \& Emerging 546 Technologies, 57, 102192. 
547 Ochoa-Velasco, C. E., Cruz-González, M., \& Guerrero-Beltrán, J. Á. (2014). Ultraviolet-C light

548 inactivation of Escherichia coli and Salmonella typhimurium in coconut (Cocos nucifera L.)

549 milk. Innovative Food Science \& Emerging Technologies, 26, 199-204.

550 Oliver, S. P., Jayarao, B. M., \& Almeida, R. A. (2005). Foodborne pathogens in milk and the dairy

551 farm environment: food safety and public health implications. Foodbourne Pathogens \&

552 Disease, 2(2), 115-129.

553 Patras, A., Bhullar, M. S., Pendyala, B., \& Crapulli, F. (2020). Ultraviolet treatment of opaque 554 liquid foods: from theory to practice. Reference Module in Food Science.

555 Pendyala, B., Patras, A., Gopisetty, V. V. S., \& Sasges, M. (2021). UV-C inactivation of 556 microorganisms in a highly opaque model fluid using a pilot scale ultra-thin film annular reactor:

557 Validation of delivered dose. Journal of Food Engineering, 294, 110403.

558 Pendyala, B., Patras, A., Gopisetty, V. V. S., Sasges, M., \& Balamurugan, S. (2019). Inactivation

559 of Bacillus and Clostridium spores in coconut water by ultraviolet light. Foodborne pathogens and 560 disease, 16(10), 704-711.

561 Pendyala, B., Patras, A., Ravi, R., Gopisetty, V. V. S., \& Sasges, M. (2020). Evaluation of UV-C 562 Irradiation Treatments on Microbial Safety, Ascorbic Acid, and Volatile Aromatics Content of 563 Watermelon Beverage. Food and Bioprocess Technology, 13(1), 101-111.

564 Pereda, J., Jaramillo, D. P., Quevedo, J. M., Ferragut, V., Guamis, B., \& Trujillo, A. J. (2008).

565 Characterization of volatile compounds in ultra-high pressure homogenized milk. International 566 dairy journal, 18(8), 826-834. 
567 Pettersson, B., Lembke, F., Hammer, P., Stackebrandt, E., \& Priest, F. G. (1996). Bacillus

568 sporothermodurans, a new species producing highly heat-resistant endospores. International

569 Journal of Systematic and Evolutionary Microbiology, 46(3), 759-764.

570 Scallan, E., Hoekstra, R. M., Angulo, F. J., Tauxe, R. V., Widdowson, M. A., Roy, S. L., ... \&

571 Griffin, P. M. (2011). Foodborne illness acquired in the United States-major

572 pathogens. Emerging infectious diseases, 17(1), 7.

573 Scheldeman, P., Goossens, K., Rodriguez-Diaz, M., Pil, A., Goris, J., Herman, L., ... \& 574 Heyndrickx, M. (2004). Paenibacillus lactis sp. nov., isolated from raw and heat-treated 575 milk. International Journal of Systematic and Evolutionary Microbiology, 54(3), 885-891.

576 Shanmugam, A., Chandrapala, J., \& Ashokkumar, M. (2012). The effect of ultrasound on the 577 physical and functional properties of skim milk. Innovative Food Science \& Emerging 578 Technologies, 16, 251-258.

579 Sizer, C. E., \& Balasubramaniam, V. M. (1999). New intervention processes for minimally 580 processed juices. Food Technology (Chicago), 53(10), 64-67.

581 Toso, B., Procida, G., \& Stefanon, B. (2002). Determination of volatile compounds in cows' milk 582 using headspace GC-MS. Journal of Dairy Research, 69(4), 569-577.

583 Tran, M. T. T., \& Farid, M. (2004). Ultraviolet treatment of orange juice. Innovative Food Science 584 \& Emerging Technologies, 5(4), 495-502.

585 Van Aardt, M., Duncan, S. E., Marcy, J. E., Long, T. E., O’Keefe, S. F., \& Nielsen-Sims, S. R. 586 (2005). Effect of antioxidant ( $\alpha$-tocopherol and ascorbic acid) fortification on light-induced flavor 587 of milk. Journal of dairy science, 88(3), 872-880. 
588 Vashisht, P., Pendyala, B., Gopisetty, V. V. S., \& Patras, A. (2021). Modeling and validation of

589 delivered fluence of a continuous Dean flow pilot scale UV system: monitoring fluence by

590 biodosimetry approach. Food Research International, 148, 110625.

591 Vazquez-Landaverde, P. A., Torres, J. A., \& Qian, M. C. (2006). Effect of high-pressure-

592 moderate-temperature processing on the volatile profile of milk. Journal of Agricultural and Food

593 chemistry, 54(24), 9184-9192.

594 Walstra, P., \& Jenness, R. (1984). Dairy chemistry \& physics. John Wiley \& Sons.

595 Ward, D. M., Patras, A., Kilonzo- Nthenge, A., Yannam, S. K., Pan, C., Xiao, H., \& Sasges, M.

596 (2019). UV-C treatment on the safety of skim milk: Effect on microbial inactivation and

597 cytotoxicity evaluation. Journal of Food Process Engineering, 42(4), e12944.

$598 \quad$ Figure legends

599 Fig. 1. Experimental setup of Dean flow UV system.

600 Fig. 2. Effect of flow rate on delivered fluence (bio studies) a) REF b) REF rate

601 Note: $\mathrm{REF}$ rate $=\mathrm{REF} /$ residence time

602 Fig. 3. Microbial inactivation per each pass of WM a) B. cereus endospores b) T1UV phage

603 Fig. 4. Variation of malondialdehyde concentration in irradiated milk samples with respect to the 604 delivered UV fluence.

605

606

607

608 
611 Table 1. Optical and Physio-chemical properties of whole milk

\begin{tabular}{ccc}
\hline Optical Properties & Value & Units \\
\hline Absorption coefficient & $23.7 \pm 0.3$ & $\mathrm{~cm}^{-1}$ \\
Scattering coefficient & $42.3 \pm 0.5$ & $\mathrm{~cm}^{-1}$ \\
Transmittance & $2.5 \mathrm{E}-22$ & $\%$ \\
\hline Physio-chemical properties & & \\
\hline Refractive Index (at 254 nm) & 1.35 & \\
$\mathrm{pH}$ & $6.73 \pm 0.17$ & $\%$
\end{tabular}

Data reported as mean \pm stdev

613

614 Table 2. Flow properties of the WM under testing

\begin{tabular}{ccccc}
\hline $\begin{array}{c}\text { Flow rate } \\
(\mathrm{L} / \mathrm{min} .)\end{array}$ & $\begin{array}{c}\text { Residence time } \\
(\mathrm{sec})\end{array}$ & $\begin{array}{c}\text { Velocity of flow } \\
(\mathrm{m} / \mathrm{sec} .)\end{array}$ & Reynolds number & Dean number \\
\hline 0.75 & 64 & 0.39 & 2890 & 648 \\
1.5 & 32 & 0.78 & 5781 & 1297 \\
3 & 16 & 1.55 & 11562 & 2595 \\
\hline
\end{tabular}

616 Table 3. Volatiles profile comparison of the untreated milk samples with irradiated samples treated 617 with UV fluence of 60 and $120 \mathrm{~mJ} / \mathrm{cm}^{2}$.

\begin{tabular}{lccc}
\hline Volatiles & Control & \multicolumn{2}{c}{ Treatments } \\
\cline { 3 - 3 } & & \multicolumn{2}{c}{ UV Fluence } \\
\cline { 3 - 4 } & & $60 \mathrm{~mJ} / \mathrm{cm}^{2}$ & $120 \mathrm{~mJ}^{2} \mathrm{~cm}^{2}$ \\
\hline Aldehydes & & $3.14 \pm 0.0^{\mathrm{c}}$ \\
2-methylpropanal & $12.37 \pm 1.32^{\mathrm{a}}$ & $4.28 \pm 0.03^{\mathrm{b}}$ & $6.05 \pm 0.49^{\mathrm{a}}$ \\
Butanal & $7.45 \pm 0.06^{\mathrm{a}}$ & $4.90 \pm 0.14^{\mathrm{b}}$ & $2.39 \pm 0.13^{\mathrm{c}}$ \\
Acetaldehyde & $5.12 \pm 0.18^{\mathrm{a}}$ & $3.35 \pm 0.18^{\mathrm{b}}$ &
\end{tabular}




$\begin{array}{lccc}\text { Pentanal } & 2.12 \pm 0.01^{\mathrm{a}} & 9.30 \pm 0.18^{\mathrm{b}} & 10.15 \pm 0.15^{\mathrm{c}} \\ \text { Hexanal } & 1.77 \pm 0.06^{\mathrm{a}} & 6.93 \pm 0.00^{\mathrm{b}} & 6.36 \pm 0.36^{\mathrm{b}} \\ \text { Heptanal } & 1.57 \pm 0.05^{\mathrm{a}} & 2.45 \pm 0.15^{\mathrm{b}} & 2.50 \pm 0.17^{\mathrm{b}} \\ \text { Citronellal } & 1.16 \pm 0.35^{\mathrm{a}} & - & 0.40 \pm 0.08^{\mathrm{b}} \\ \text { Octanal } & 0.91 \pm 0.08^{\mathrm{a}} & 0.56 \pm 0.15^{\mathrm{b}} & 0.46 \pm 0.09^{\mathrm{c}} \\ \text { 2-Decenal } & 0.74 \pm 0.02^{\mathrm{a}} & - & - \\ \text { 3-methyl butanal } & 0.58 \pm 0.03^{\mathrm{a}} & - & -\end{array}$

\begin{tabular}{lccc}
\hline Total & $34.27 \pm 1.84^{\mathrm{a}}$ & $34.61 \pm 0.70^{\mathrm{a}}$ & $35.09 \pm 1.36^{\mathrm{a}}$ \\
\hline Alcohols & & & \\
1-Propanol & $6.32 \pm 0.37^{\mathrm{a}}$ & $7.90 \pm 0.27^{\mathrm{b}}$ & $7.82 \pm 0.37^{\mathrm{b}}$ \\
n-butanol & $5.83 \pm 0.61^{\mathrm{a}}$ & $12.78 \pm 0.08^{\mathrm{b}}$ & $13.88 \pm 0.57^{\mathrm{b}}$ \\
1-Hexanol & $3.60 \pm 0.28^{\mathrm{a}}$ & $5.36 \pm 0.19^{\mathrm{b}}$ & $2.12 \pm 0.33^{\mathrm{a}}$ \\
3-heptanol & $2.01 \pm 0.04^{\mathrm{a}}$ & $1.43 \pm 0.06^{\mathrm{b}}$ & $1.09 \pm 0.07^{\mathrm{c}}$ \\
1-nonanol & $1.47 \pm 0.06^{\mathrm{a}}$ & - & - \\
Methyl eugenol & $1.44 \pm 0.60^{\mathrm{a}}$ & $1.49 \pm 0.24^{\mathrm{a}}$ & $1.59 \pm 0.00^{\mathrm{b}}$ \\
Ethyl propanoate & $0.48 \pm 0.03^{\mathrm{a}}$ & $3.40 \pm 0.02^{\mathrm{b}}$ & $4.11 \pm 0.05^{\mathrm{c}}$ \\
1-Decanol & $0.44 \pm 0.03^{\mathrm{a}}$ & - & - \\
1 -octanol & $0.36 \pm 0.10^{\mathrm{a}}$ & - & - \\
\hline Total & $21.95 \pm 1.21^{\mathrm{a}}$ & $32.36 \pm 0.60^{\mathrm{b}}$ & $30.61 \pm 1.54^{\mathrm{b}}$ \\
\hline
\end{tabular}

\section{Ketones}

\begin{tabular}{lccc} 
butane-2,3-dione & $2.98 \pm 0.25^{\mathrm{a}}$ & $1.73 \pm 0.01^{\mathrm{b}}$ & $1.67 \pm 0.00^{\mathrm{b}}$ \\
Pentan-2-one & $1.59 \pm 0.01^{\mathrm{a}}$ & $1.31 \pm 0.02^{\mathrm{b}}$ & $1.4 \pm 0.01^{\mathrm{b}}$ \\
Delta Nonalactone & $1.52 \pm 0.26^{\mathrm{a}}$ & $2.19 \pm 0.14^{\mathrm{b}}$ & $1.18 \pm 0.15^{\mathrm{c}}$ \\
Nonan-2-one & $1.32 \pm 0.39^{\mathrm{a}}$ & $1.17 \pm 0.00^{\mathrm{a}}$ & $1.08 \pm 0.08^{\mathrm{a}}$ \\
Butan-2-one & $1.21 \pm 0.04^{\mathrm{a}}$ & $1.21 \pm 0.04^{\mathrm{a}}$ & $1.60 \pm 0.11^{\mathrm{b}}$ \\
2,3-Pentanedione & $0.82 \pm 0.03^{\mathrm{a}}$ & $1.3 \pm 0.02^{\mathrm{b}}$ & $1.37 \pm 0.31^{\mathrm{b}}$ \\
2-Heptanone & $0.61 \pm 0.03^{\mathrm{a}}$ & $0.55 \pm 0.07^{\mathrm{a}}$ & $0.51 \pm 0.03^{\mathrm{a}}$ \\
Undecan-2-one & $0.63 \pm 0.02^{\mathrm{a}}$ & $0.63 \pm 0.34^{\mathrm{a}}$ & $0.52 \pm 0.17^{\mathrm{a}}$ \\
\hline Total & $10.68 \pm 0.95^{\mathrm{a}}$ & $10.09 \pm 0.55^{\mathrm{a}}$ & $9.33 \pm 0.52^{\mathrm{b}}$ \\
\hline
\end{tabular}

Esters

Methyl

$5.09 \pm 0.06^{\mathrm{a}}$

$2.06 \pm 0.10^{\mathrm{b}}$

$1.64 \pm 0.0^{\mathrm{c}}$ 
2-methylbutanoate

$\begin{array}{lccc}\text { Butyl acetate } & 1.68 \pm 0.08^{\mathrm{a}} & 1.31 \pm 0.04^{\mathrm{b}} & 1.15 \pm 0.04^{\mathrm{c}} \\ \text { Ethyl isobutyrate } & 1.24 \pm 0.18^{\mathrm{a}} & 2.00 \pm 0.05 \mathrm{~b} & 1.1 \pm 0.03 \mathrm{a} \\ \text { Ethyl butyrate } & 1.18 \pm 0.12^{\mathrm{a}} & 4.79 \pm 0.15 \mathrm{~b} & 6.34 \pm 0.25^{\mathrm{c}} \\ \text { Isopropyl acetate } & 0.43 \pm 0.10^{\mathrm{a}} & 3.38 \pm 0.08 \mathrm{~b} & 2.91 \pm 0.40^{\mathrm{c}} \\ \text { Ethyl Acetate } & 0.83 \pm 0.07^{\mathrm{a}} & - & - \\ \text { Isoamyl acetate } & 0.75 \pm 0.10^{\mathrm{a}} & 0.86 \pm 0.03 \mathrm{a} & - \\ \text { Butyl butanoate } & 0.58 \pm 0.21^{\mathrm{a}} & - & - \\ \text { ethyl heptanoate } & 0.49 \pm 0.02^{\mathrm{a}} & - & -\end{array}$

Total

$12.27 \pm 0.64^{\mathrm{a}}$

$14.5 \pm 0.45^{\mathrm{b}}$

$14.02 \pm 0.97^{\mathrm{c}}$

Carboxylic acid

2-methylpropanoic

$4.18 \pm 0.28^{\mathrm{a}}$

$5.38 \pm 0.01^{\mathrm{b}}$

$5.95 \pm 0.20^{b}$

acid

Acetic Acid

$1.67 \pm 0.07^{\mathrm{a}}$

Propanoic acid

$0.81 \pm 0.31^{\mathrm{a}}$

Hexanoic acid

$0.62 \pm 0.01^{\mathrm{a}}$

$0.57 \pm 0.17^{\mathrm{a}}$

$0.50 \pm 0.17^{\mathrm{b}}$

Octanoic Acid

$0.84 \pm 0.13^{\mathrm{a}}$

$0.59 \pm 0.23^{b}$

$0.59 \pm 0.07^{\mathrm{b}}$

Butanoic acid

$0.92 \pm 0.01^{\mathrm{a}}$

Dodecanoic acid

$0.31 \pm 0.05^{\mathrm{a}}$

Total

$9.35 \pm 0.71^{\mathrm{a}}$

$6.54 \pm 0.27^{b}$

$7.04 \pm 0.31^{\mathrm{c}}$

Terpenes

$\alpha$-Terpinene

$0.84 \pm 0.02^{\mathrm{a}}$

$0.94 \pm 0.19^{\mathrm{a}}$

$2.12 \pm 0.01^{\mathrm{b}}$

$\alpha$-Phellandrene

$1.38 \pm 0.23^{\mathrm{a}}$

$1.45 \pm 0.61^{\mathrm{a}}$

$1.67 \pm 0.15^{\mathrm{a}}$

Total

$2.22 \pm 0.25^{\mathrm{a}}$

$2.39 \pm 0.80^{\mathrm{a}}$

$3.79 \pm 0.14^{\mathrm{b}}$

Grand Total

$90.26 \pm 1.31^{\mathrm{a}}$

$97.09 \pm 0.77^{b}$

$95.76 \pm 2.38^{\mathrm{c}}$

Values are mean \pm standard deviation, $n=3$, mean values in a row with different letters are

619 significantly different at $\mathrm{p}<0.05$.

620

621 Table 4. $\mathrm{E}_{\mathrm{EO}}$ of a Dean flow system to inactivate targeted microorganism under flow rate

622 conditions. 


\begin{tabular}{ccc}
\hline T1 UV phage & 47.55 & $1.19 \pm 0.11$ \\
Bacillus cereus ATCC 14579 & 47.55 & $2.67 \pm 0.12$ \\
Bacillus cereus ATCC 14579 & 23.77 & $2.94 \pm 0.05$ \\
Bacillus cereus ATCC 14579 & 11.88 & $3.27 \pm 0.48$
\end{tabular}

\section{Figures}

\section{Fig. 1}

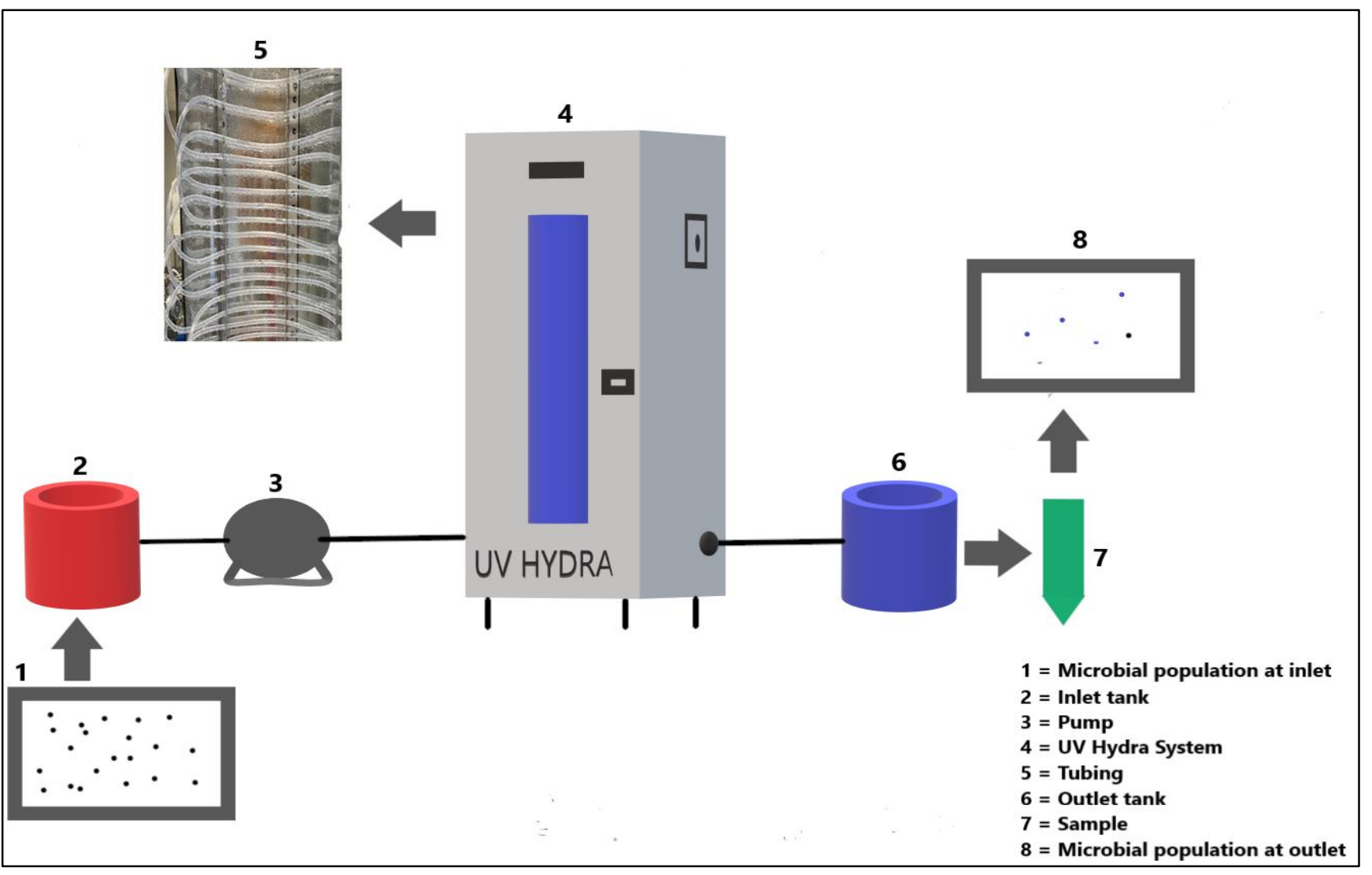

627 
Fig. 2

a)

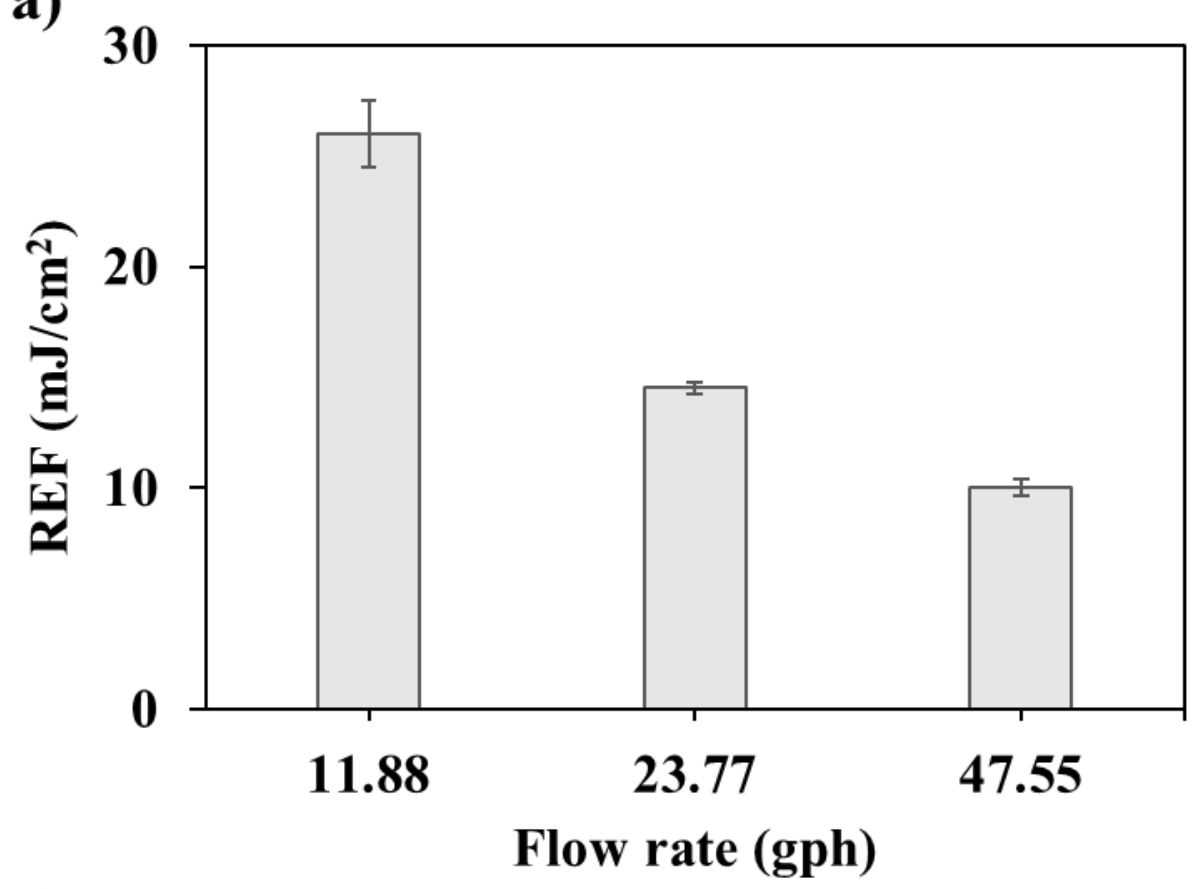

b)

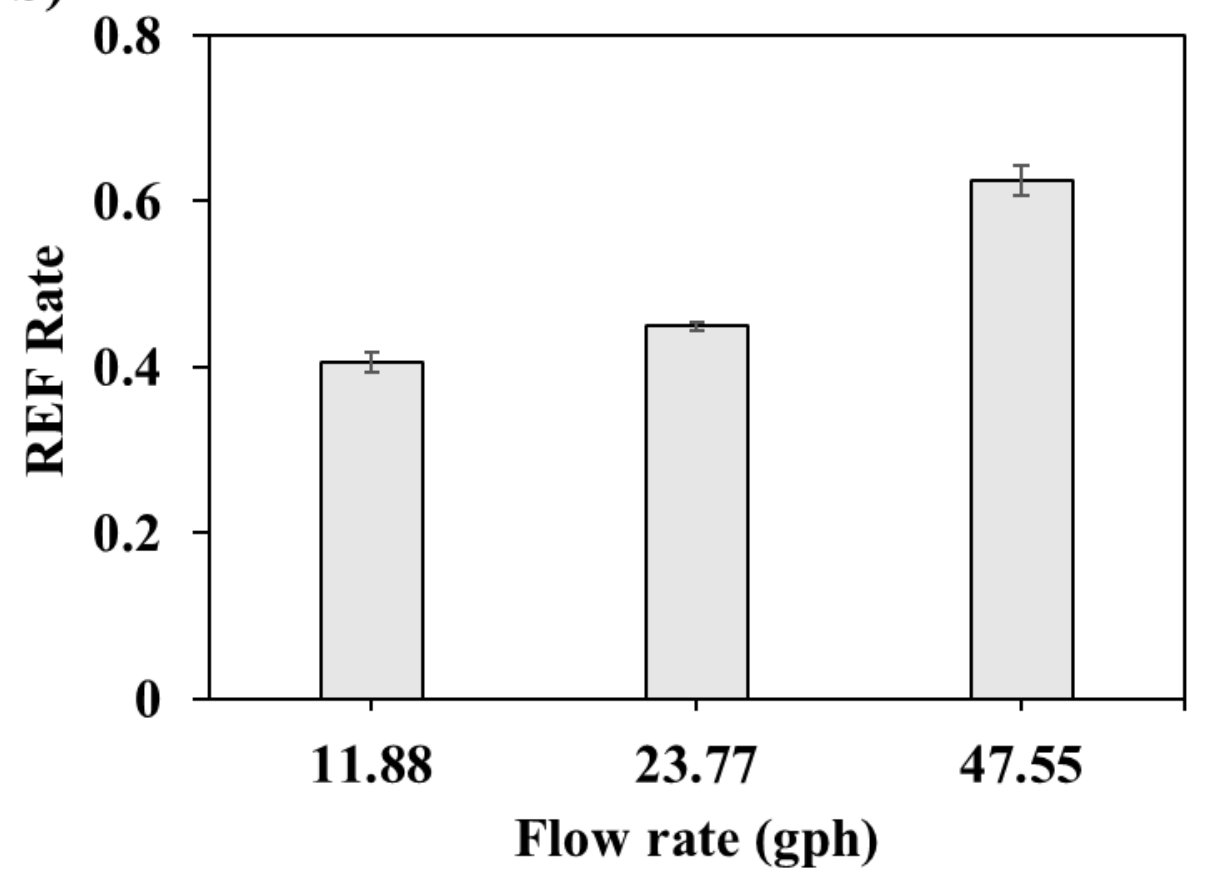


$634 \quad$ Fig. 3
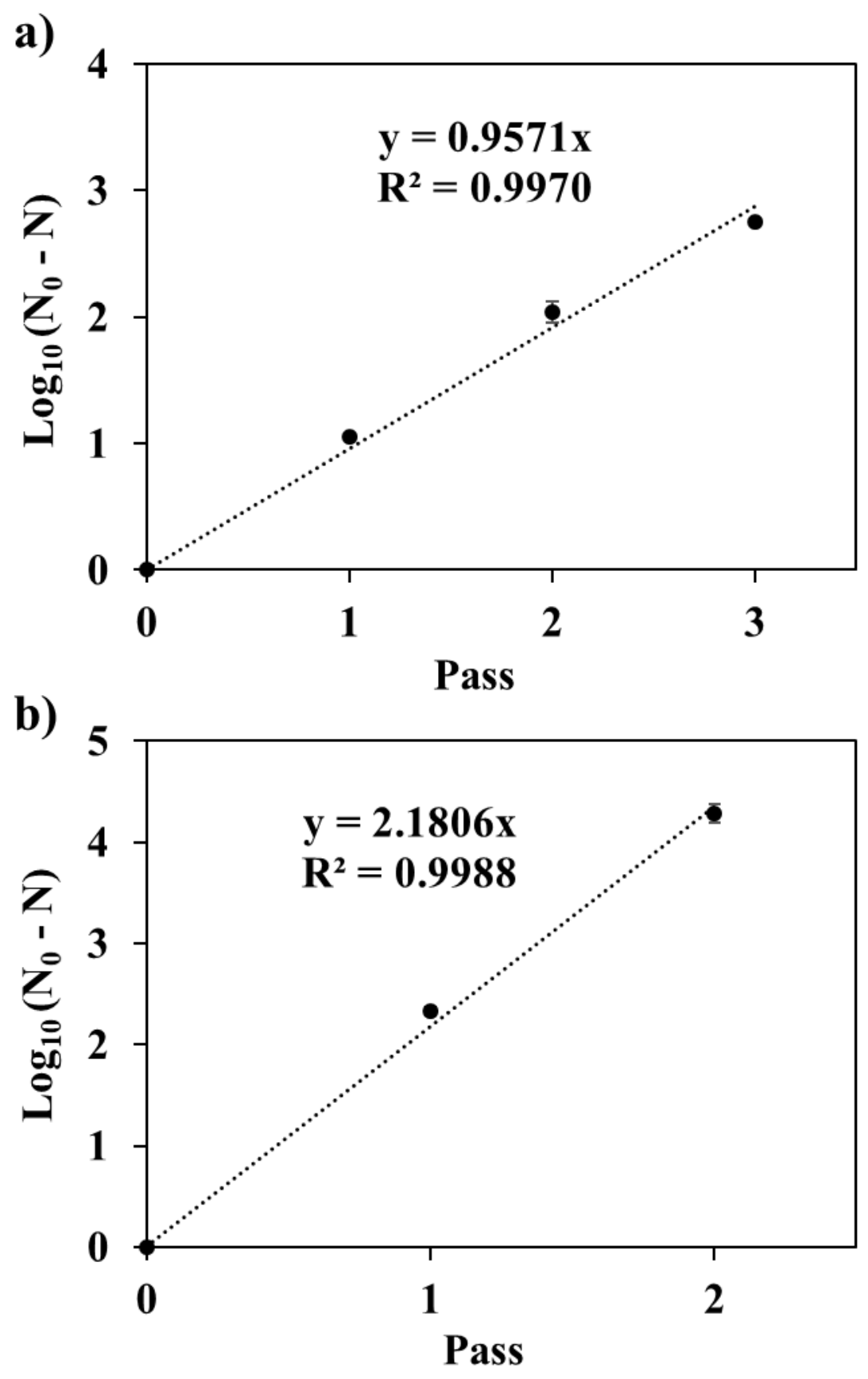
638 Fig. 4

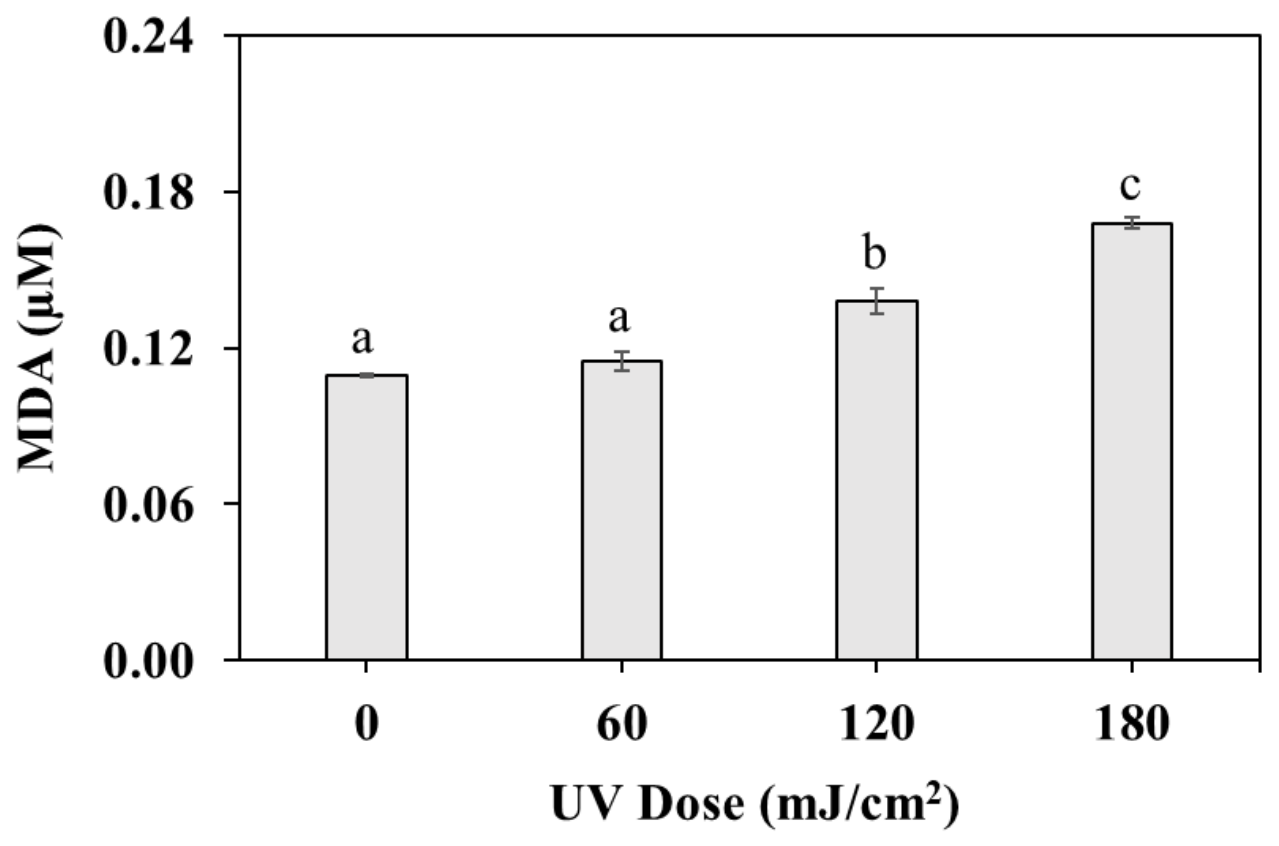




\section{CRediT authorship contribution statement}

Pranav Vashisht: Conceptualization, Methodology, Investigation, Visualization, Writing original draft. Brahmaiah Pendyala: Conceptualization, Methodology, Investigation, Visualization, Writing - original draft, Supervision. Ankit Patras: Conceptualization, Methodology, Supervision, Funding acquisition. Vybhav Vipul Sudhir Gopisetty: Conceptualization, Methodology. Ramasamy Ravi: Methodology, Investigation. 